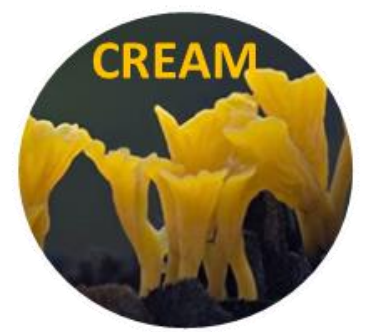

\title{
A preliminary checklist of fungi of Gujarat State, India
}

\section{Rajput KS ${ }^{1 *}$, Koyani $\mathrm{RD}^{1}$, Patel $\mathrm{HR}^{1}$, Vasava $\mathrm{AM}^{1}$, Patel $\mathrm{RS}^{1}$, Patel $\mathrm{AD}^{1}$ and Singh $\mathbf{A P}^{2}$}

${ }^{1}$ Department of Botany, Faculty of Science, The Maharaja Sayajirao University of Baroda, Vadodara 390002,

${ }^{2}$ Chief Conservator of Forest, Wild Life Circle, Sardadar Baug, Junagadh 362001, India.

*Address for correspondence: ksrajput-botany@msubaroda.ac.in

Rajput KS, Koyani RD, Patel HP, Vasava AM, Patel RS, Patel AD, Singh AP 2015 - Preliminary checklist of fungi of Gujarat State, India. Current Research in Environmental \& Applied Mycology 5(4), 285-306, Doi 10.5943/cream/5/4/1

\begin{abstract}
The state of Gujarat is well known for its contrasting ecoregions such as moist deciduous forests and deserts. This paper deals with the documentation of fungi of Gujarat state. Field studies are carried out since 2007 in different parts of Gujarat to study the wood rot fungi that destroy wood logs in different forests. During these studies we noticed a great lacuna in documented record of fungi occurring in Gujarat. Here we provide, for the first time, a literature-based preliminary checklist of the fungi occurring in the state that is supplemented with our original field work and observations. It includes 334 species of 158 genera belonging to 78 families, which are further categorized into: Ascomycota (59 genera), Basidiomycota (85 genera), Chytridiomycota (2 genera), Oomycota (3 genera), "Zygomycota" (4 genera) and Myxomycota (5 genera). Our extensive field work from January 2014 to January 2015 resulted in the collection of 98 fungal species out of which 22 species are new record for Gujarat.
\end{abstract}

Key words - Biodiversity - mycobiota - species list - taxonomy

\section{Introduction}

Fungi are one of the important groups of saprophytes that play a fundamental role in the forest ecosystem by recycling carbon stored in the form of complex organic matter (Fazio et al. 2010, Sanghvi et al. 2013, Koyani \& Rajput 2014). They are also important biotechnological tools used in the production of various enzymes and secondary metabolites. They are utilised for biological control of various pests, in paper and pulp industry as well as in the process of bioremediation of xenobiotic compounds (Salvachúa et al. 2011, Koyani et al. 2013, 2014, Lee et al. 2015). Considering the economic aspects and the significant role, which fungi are going to play in near future, several countries are working hard for documentation of fungal biodiversity and are screening them for various products for the economic growth of the country (Mueller et al. 2004). Several monographs, reports, field manuals and pictorial handbooks are available for their identification. On the contrary, no such information is available on the fungal diversity of Gujarat state of India. A few sporadic reports on the occurrence of new species or fungal pathogens of agricultural crops were published by earlier workers (GEC 1996, Singh \& Beena 2003, Arya et al. 2008, Saxena \& Ratnthora 2009, Gajjar et al. 2011, 
Kumar et al. 2011, Bhavsar et al. 2012, Nagadesi \& Arya 2012, 2013, Nawal et al. 2012, Thaker \& Maharsh 2012, Assudani et al. 2013, Dhingani et al. 2013, Katara et al. 2013, Khan et al. 2013, Khokhar et al. 2013, Korat et al. 2013, Nasit et al. 2013, Panchal et al. 2013, Shah et al. 2013, Yadav et al. 2013). However, no special efforts were made to document the fungal diversity of the state. Moreover, a perusal of literature indicates that most of these studies are carried out in the recent years. Among the earlier work, Gujarat Ecological Commission (GEC) has the significant contribution on this aspect and documented a list of 164 fungal species occurring in Gujarat state.

Gujarat is bounded by the Arabian Sea at the southwest and geographically located between $20^{\circ}$ $6^{\prime} \mathrm{N} \mathrm{t}^{\circ} 24^{\circ} 42^{\prime} \mathrm{N}$ and $68^{\circ} 10^{\prime} \mathrm{E}$ to $74^{\circ} 28^{\prime} \mathrm{E}$. The total geographical area of the state comprises of land mass of $1,96,204 \mathrm{~km}^{2}(75,755 \mathrm{sq}$ miles) from which a little or less than 20 lakh hector of land is under forest cover which is unevenly distributed but the major concentration is found on the eastern hilly Saurashtra region. The temperature of the state ranges from $1^{\circ} \mathrm{C}$ to $46^{\circ} \mathrm{C}$. The high variation in geophysical and climatic conditions resulted in the formation of different forest types. The rainfall received in the state varies from region to region and the northern part of the state is a desert.

Gujarat is endowed with a great diversity of natural ecosystems ranging from moist deciduous forests to pure desert conditions (Tadvi 2013). According to Champion \& Seth (1968), out of the 16 different forest types seen in India, four are found in Gujarat: 1) tropical moist deciduous forest; 2) tropical dry deciduous forest; 3) northern tropical thorn forest; 4) littoral and swamp forest. Tropical moist deciduous forests occur at the southern part of the state where the most common species found is Tectona grandis (teak), which need the moderate rainfall. Terminalia tomestosa and Anogeissus latifolia are common associates of teak in tropical moist deciduous forests. Tropical dry deciduous forests are found in central and Saurashtra region of the state. These forests show mixed growth of trees where Tectona grandis, Boswellia serrata, Anogeissus latifolia, Wrightia tinctoria, Euphorbia nerrifolia and Diospyros malanoxylon are very common. The area is also known for Savanna type of grass lands. Northern tropical thorn forests occur commonly in Kutch, Junagadh, Rajkot and Bhavnagar Districts and are characterized by the growth of Acacia arabica, Acacia nilotica, A. senegal, A. catechu, Acacia leucophloea, Capparis aphylla and Zizyphus mauratiana. Some parts of Kutch, Jamnagar and Junagadh Districts have littoral swamp forests where mangroves are found. The main species found in these forests are Avicennia marina, Rhizophora mucronata and Ceriops tagal.

In spite of this geographic, climatic and vegetational diversity, information on the fungal diversity of the state is scanty and no comprehensive list is available for the Gujarat state. Our study is focused on exploration and documentation of fungal diversity of the state. It provides a preliminary checklist for the first time that lists 334 species based on available literature supplemented with our own data.

\section{Materials \& Methods}

\section{Material Collection}

Fruiting bodies, infected plant parts, degrading litter or decaying wood samples were collected from 31 out of the 33 districts of the Gujarat state. Collected samples were packed in sterile poly ethylene bags for further study and cultivation. Collection sites included undisturbed forests, secondary forests, crop fields, bush fallows and farmers' trails. The morphological characteristic of macro-fungi and their fruiting bodies were recorded and photographed in their natural habitat with digital camera. For microscopic fungi, samples were collected and inoculated on PDA or MEA media, pure cultures were established by serial transfer. Their mycelial and spore characteristics were studied by staining with $1 \%$ aqueous solution of Congo red and mounted in $3 \%$ aqueous $\mathrm{KOH}$. Photomicrographs were obtained with a Leica trinocular research microscope attached with a Leica DFC295 digital camera.

\section{Isolation, purification and identification}

For the isolation of plant pathogenic and wood rot fungi, infected samples were excised with a surgical blade or chisel and hammer and immediately packed in sterile poly ethylene bags and brought to the laboratory. After suitable trimming, they were surface sterilized by $0.1 \% \mathrm{HgCl}_{2}$ for $40-45$ seconds, washed thoroughly with distilled water followed by $70 \%$ ethanol for a few seconds. 

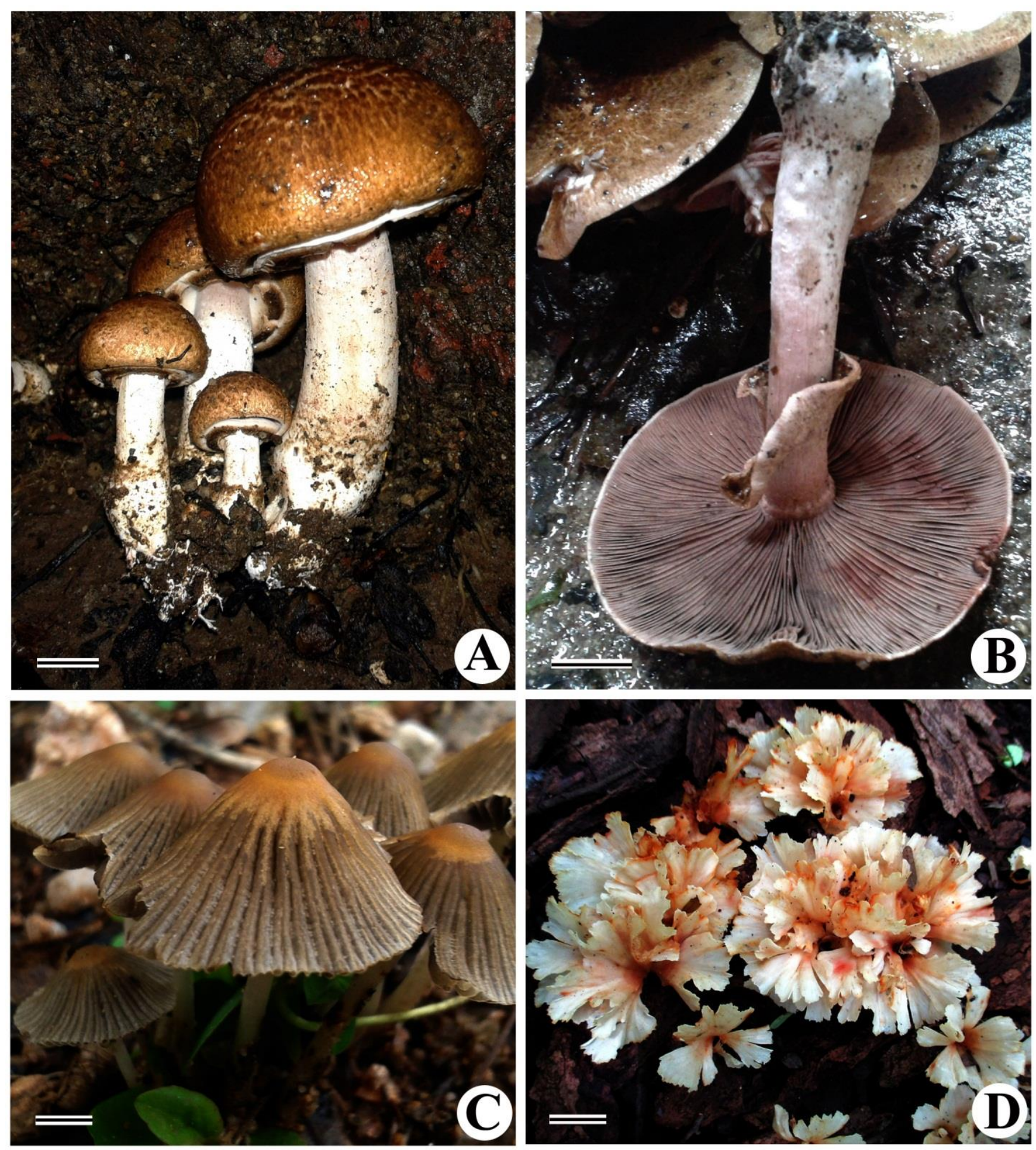

Fig. 1A-D - Fungal fruiting bodies. A: Agaricus silvaticus, B: Agaricus silvaticus, C: Coprinellus plicatilis, D: Podoscypha petalodes. Figure 1A-D: Scale bar $=10 \mathrm{~mm}$

Thereafter, these samples were inoculated on Potato Dextrose Agar (PDA) and Malt Extract Agar (MEA) media and incubated at $27{ }^{\circ} \mathrm{C}$. Pure cultures were established by serial transfer and stored at 4 ${ }^{\circ} \mathrm{C}$ in a refrigerator.

Morphology-based taxonomic identification was carried out by using standard references. After morpho-taxonomic identification, wherever doubt existed, such cultures or fruiting bodies (in case of macro-fungus) were identified by molecular methods. 

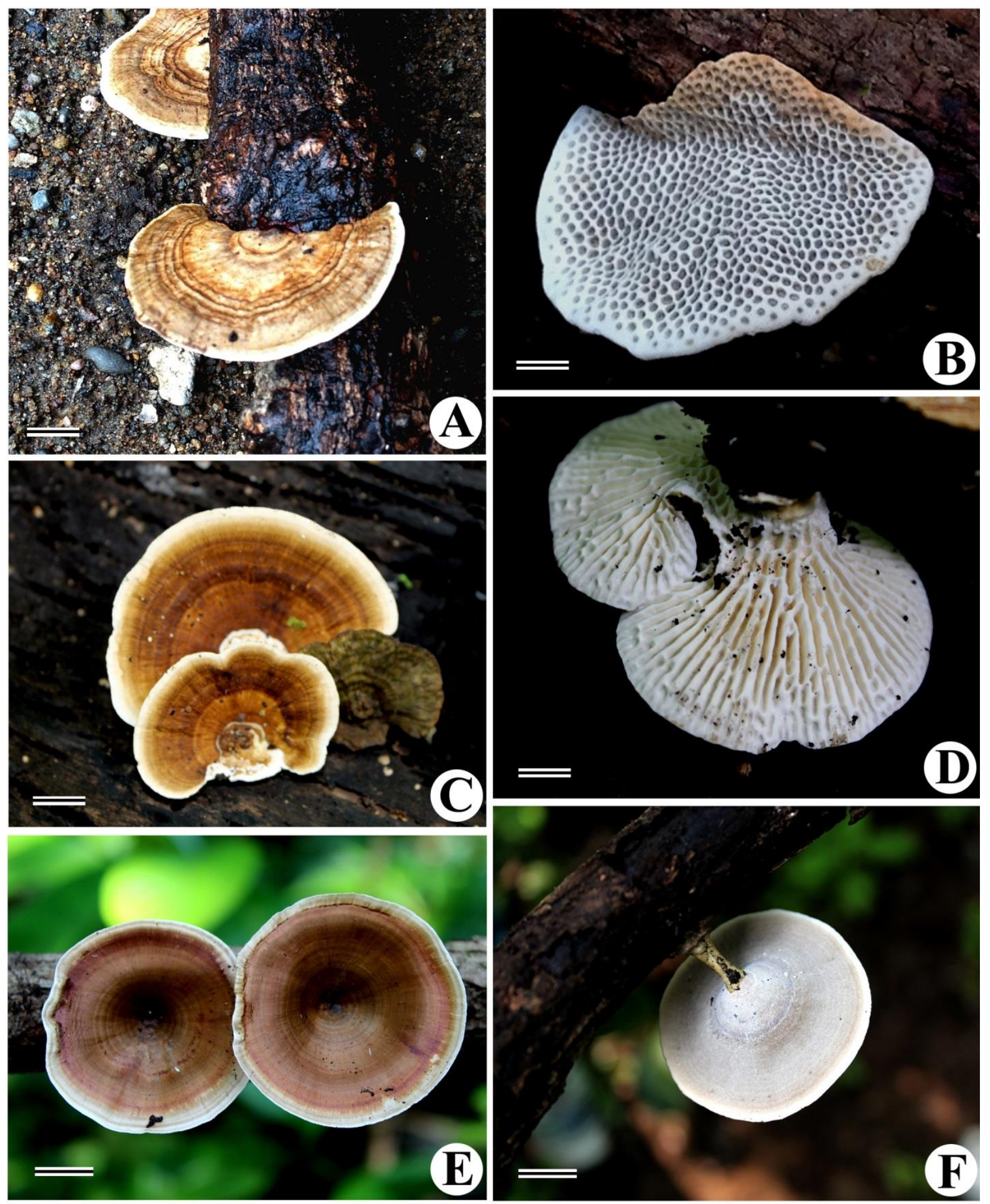

Fig. 2A-F - Fungal fruiting bodies. A: Hexagonia nitida (upper view), B: Hexagonia nitida (lower part), C: Lenzites betulina (upper view), D: L. betulina (lower view), E: Microporus vernicipes (upper view), F: M. vernicipes (lower view). Figure 2A, B, E, F: Scale bar $=10 \mathrm{~mm}, \mathrm{C}, \mathrm{D}:$ Scale bar $=5 \mathrm{~mm}$.

\section{Molecular identification}

For molecular identification, genomic DNA was extracted using fresh mycelia or fruiting bodies of fungi. Extraction was carried out using a Plant/Fungi DNA isolation kit (Sigma Cat\# E5038) and manually employing the procedure described by Plaza et al. (2014). PCR was carried out using 1x final 

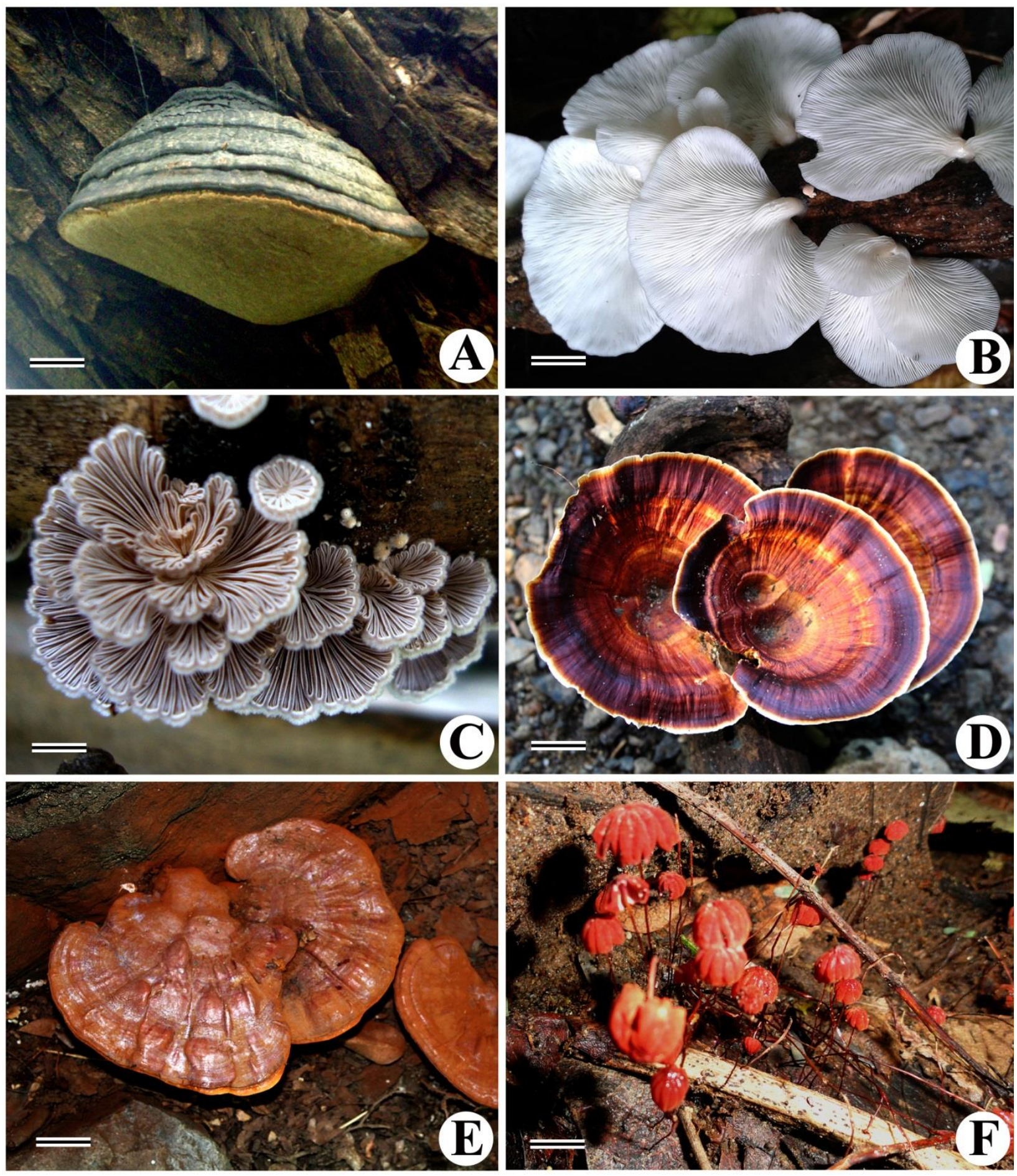

Fig. 3A-F - Fungal fruiting bodies. A: Phellinus igniarius, B: Pleurotus pulmonarius, C: Schizophyllum commune, D: Microporus xanthopus, E: Ganoderma applanatum, F: Marasmius haematocephalus. Figure 3A: Scale bar $=20 \mathrm{~mm}, \mathrm{~B}:$ Scale bar $=8 \mathrm{~mm}, \mathrm{C}, \mathrm{D}, \mathrm{F}:$ Scale bar $=10 \mathrm{~mm}, \mathrm{E}$ : Scale bar $=15 \mathrm{~mm}$.

concentration of Ready Mix ${ }^{\mathrm{TM}}$ Taq PCR Reaction Mix (Sigma) and, template DNA (50 ng/ $\mu \mathrm{l}$ ). Amplification of the DNA was performed by using a Veriti ${ }^{\circledR}$ thermal cycler (Applied Biosystems, Foster City, CA, USA). The ITS region was amplified using the primers ITS 1 and ITS 4 as described by White et al. (1990). The amplified products were purified using Purelink ${ }^{\mathrm{TM}}$ Quick PCR Purification kit (Cat\# K310001). Purified PCR products were sent for sequencing to Eurrofins Genomics India Pvt. Ltd., Bangalore. 

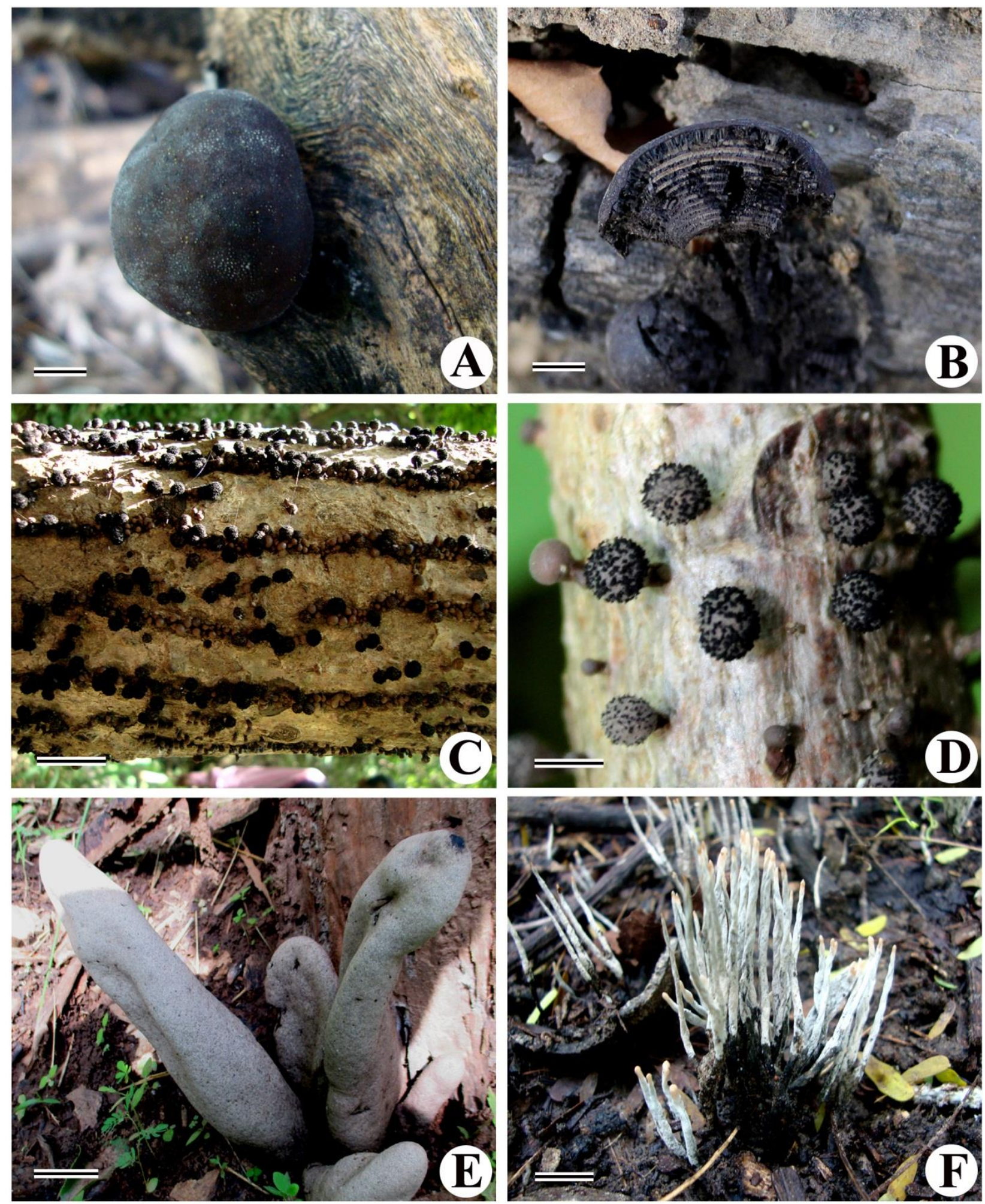

Fig. 4A-F - Fungal fruiting bodies. A: Daldinia concentrica, B: Daldinia concentrica (Section), C: Hypoxylon fragiforme, D: Enlarged view of Hypoxylon fragiforme, E: Xylaria regalis, F: Xylaria hypoxylon. Figure 4A, B, E, F: Scale bar $=5 \mathrm{~mm}, \mathrm{C}, \mathrm{D}:$ Scale bar $=12 \mathrm{~mm}$

The generated sequences were used for BLAST search in the GenBank database (www.ncbi.nlm.nih.gov) for identification of the fungal species. Identification was done by $99 \%$ basepair match of the sequence obtained to the closest available reference sequences. After molecular identification, characteristics of the identified fungal species were compared with the literature to further confirm the identity of our isolate. 

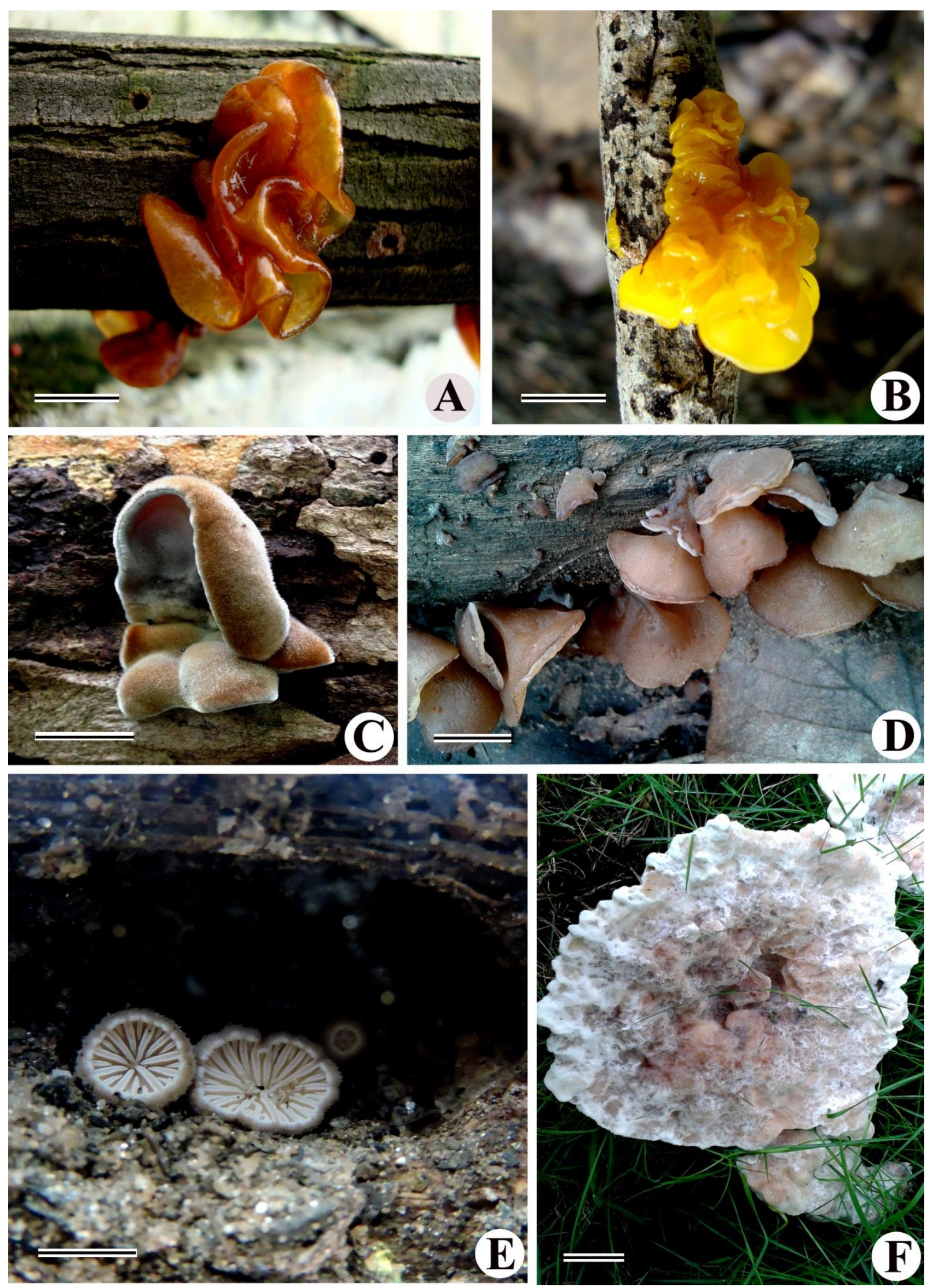

Fig. 5A-F - Fungal fruiting bodies. A: Tremella foliacea, B: T. mesenterica, C: Auricularia polytricha, D: A. auricula-judae, E: Crepidotus fimbriatus, F: Amylosporus campbellii. Figure 5A, B: Scale bar = $15 \mathrm{~mm}, \mathrm{C}$, D: Scale bar $=10 \mathrm{~mm}, \mathrm{E}:$ Scale bar $=5 \mathrm{~mm}, \mathrm{~F}:$ Scale bar $=20 \mathrm{~mm}$. 

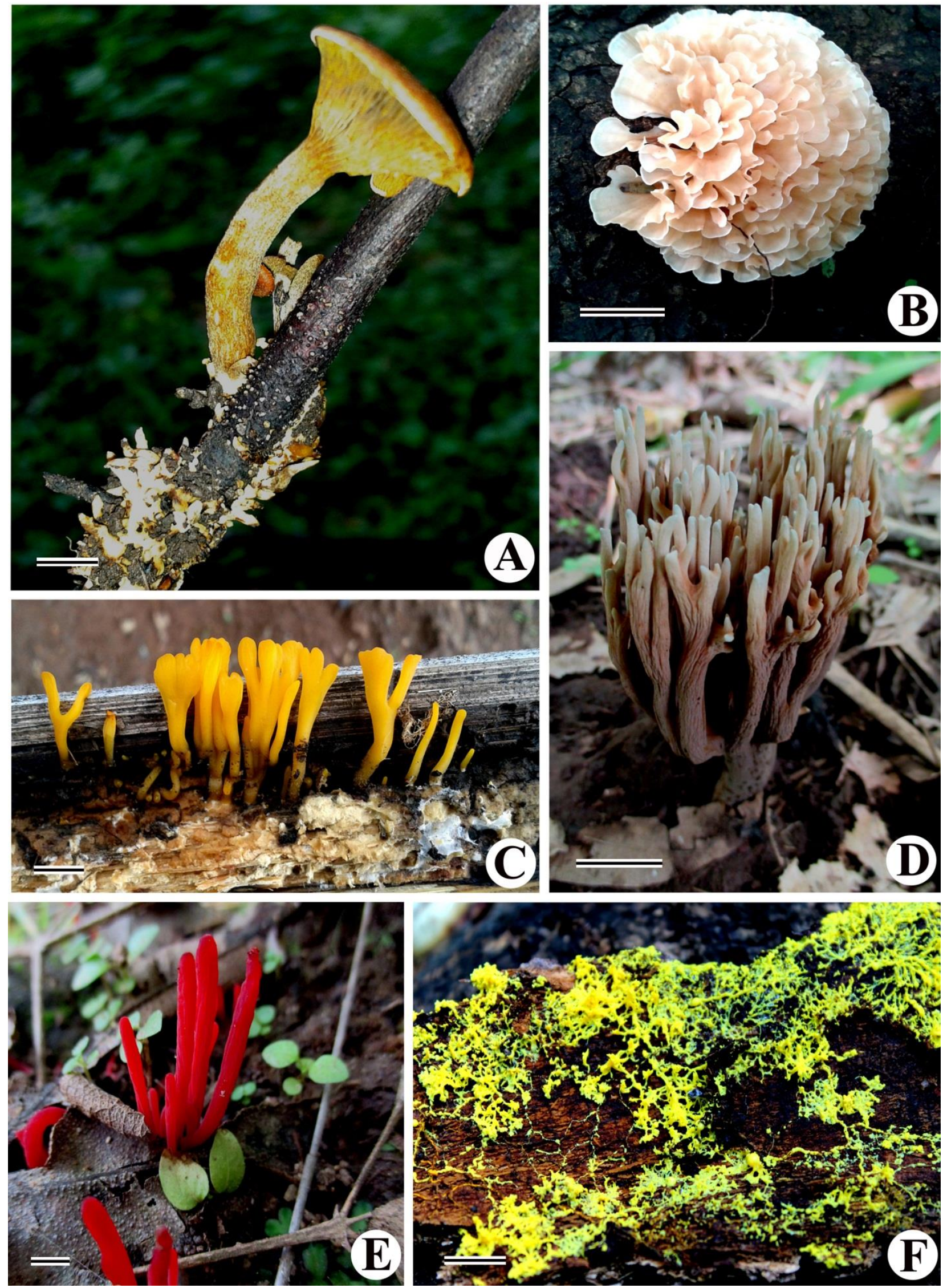

Fig. 6A-F - Fungal fruiting bodies. A: Gerronema subclavatum, B: Sparassis crispa, C: Dacryopinax spathularia, D: Ramaria Formosa, E: Clavaria rosea, F: Physarum polycephalum. Figure 6A, E, F: Scale bar $=10 \mathrm{~mm}, \mathrm{~B}, \mathrm{D}:$ Scale bar $=20 \mathrm{~mm}, \mathrm{C}:$ Scale bar $=15 \mathrm{~mm}$. 
Table 1 List of fungal species reported from different parts of Gujarat. Species names in bold indicate those collected in the present study while those with asterisk indicate new reports for the state. Abbreviations: GSBTM = Gujarat State Biotechnology Mission, GEC = Gujarat Ecological Commission.

\begin{tabular}{|c|c|c|c|c|}
\hline Order & Family & Name of the species & Distribution & References \\
\hline \multicolumn{5}{|c|}{ KINGDOM: PROTOZOA } \\
\hline \multicolumn{5}{|c|}{ PHYLUM: MYXOMYCOTA } \\
\hline \multirow[t]{4}{*}{ Physarales } & Didymiaceae & & & Ranade et al. 2009 \\
\hline & & Lepidoderma effusum Rokade \& Nanir & Dang, Junagadh & \\
\hline & & Diderma cingulatum Nann.-Bremek & Dang, Junagadh & Ranade et al. 2009 \\
\hline & Physaraceae & Physarum polycephalum Schwein $* *$ & Waghai, Baroda & \\
\hline \multirow{2}{*}{ Liceales } & Liceaceae & & & \\
\hline & & Licea elloriana Nanir \& Rokade & Dang, Ratanmahal & Ranade et al. 2009 \\
\hline \multirow[t]{2}{*}{ Stemonitales } & Stemonitidaceae & & & \\
\hline & & Stemonitis fusca Roth $* *$ & Junagadh, Dang & \\
\hline \multicolumn{5}{|c|}{ KINGDOM: STRAMINIPILA } \\
\hline \multicolumn{5}{|c|}{ PHYLUM: OOMYCOTA } \\
\hline \multirow[t]{8}{*}{ Peronosporales } & Albuginaceae & & & \\
\hline & & Albugo bliti (Biv.) Kuntz & Dang, Junagadh & GEC 1996 \\
\hline & & Albugo candida (Pers.) Roussel & Dang, Ratanmahal & GEC 1996 \\
\hline & & Albugo evolvuli (Damle) Safeeulla \& Thirum. & Dang, Pavagadh & GEC 1996 \\
\hline & & Albugo platensis (Speg.) Swingle & Dang & GEC 1996 \\
\hline & & Albugo portulacae (DC.) Kuntze & Dang, Jassore & GEC 1996 \\
\hline & Peronosporaceae & Sclerophthora macrospora (Sacc.) Thirum. & Dang & GEC 1996 \\
\hline & & Sclerospora graminicola (Sacc.) J. Schröt. & Dang & GEC 1996 \\
\hline \multicolumn{5}{|c|}{ KINGDOM : EUMYCOTA } \\
\hline \multicolumn{5}{|c|}{ PHYLUM : ASCOMYCOTA } \\
\hline \multirow[t]{4}{*}{ Botryosphaeriales } & Botryosphaeriaceae & $\begin{array}{l}\text { Botryosphaeria dothidea (Moug.) Ces. \& De } \\
\text { Not. }\end{array}$ & Jessore, Dang & GSBTM 2013 \\
\hline & & $\begin{array}{l}\text { Lasiodiplodia crassispora T.I. Burgess \& } \\
\text { Barber }\end{array}$ & Junagadh, Thol Junagadh & GSBTM 2013 \\
\hline & & $\begin{array}{l}\text { Lasiodiplodia theobromae (Pat.) Griffon \& } \\
\text { Maubl. }\end{array}$ & $\begin{array}{l}\text { Thol, Jessore, Junagadh } \\
\text { Gandhinagar, }\end{array}$ & GSBTM-2013 \\
\hline & & Macrophomina phaseolina (Tassi) Goid. & Rajkot, Navsari & $\begin{array}{l}\text { Thaker et al. 2012; Dhibgani et al. } \\
2013\end{array}$ \\
\hline \multirow[t]{5}{*}{ Capnodiales } & Asterinaceae & Asterina delicatula Syd., P. Syd. \& Bal & Dang & GEC 1996 \\
\hline & & Asterina lawsoniae Henn. \& E. Nyman & Dang & GEC 1996 \\
\hline & & Asterina spissa Syd. \& P. Syd. & Dang & GEC 1996 \\
\hline & Capnodiaceae & Capnodium annonae Pat. & Dang & GEC 1996 \\
\hline & Davidiellaceae & $\begin{array}{l}\text { Cladosporium allicinum (Fr.) Bensch, U. Braun } \\
\& \text { Crous }\end{array}$ & Anand & Khan et al. 2013 \\
\hline
\end{tabular}




\begin{tabular}{|c|c|c|c|c|}
\hline Order & Family & Name of the species & Distribution & References \\
\hline & \multirow{20}{*}{ Mycosphaerellaceae } & $\begin{array}{l}\text { Cladosporium cladosporioides (Fresen.) G.A. } \\
\text { de Vries }\end{array}$ & Kutch & GSBTM-2013 \\
\hline & & Cladosporium herbarum (Pers.) Link & $\begin{array}{l}\text { Panchmahal, } \\
\text { Dang }\end{array}$ & Nagadesi \& Arya, 2012 \\
\hline & & Cladosporium sp. & Jessore, Polo forest & GSBTM 2013 \\
\hline & & Cladosporium ziziphi P. Karst. \& Roum. & Dang & GEC 1996 \\
\hline & & Cercospora arachidicola Hori & Dang, Ratanmahal & GEC 1996 \\
\hline & & Cercospora achyranthina Thirum. \& Chupp & Dang & GEC 1996 \\
\hline & & $\begin{array}{l}\text { Passalora calotropidis (Ellis \& Everh.) U. } \\
\text { Braun }\end{array}$ & Dang & GEC 1996 \\
\hline & & $\begin{array}{l}\text { Pseudocercospora cannabina (Wakef.) } \\
\text { Deighton }\end{array}$ & Dang, Panchmahal & GEC 1996 \\
\hline & & Cercospora celosiae Syd. & Dang, Ratanmahal & GEC 1996 \\
\hline & & Cercospora cocculi Syd. & Dang & GEC 1996 \\
\hline & & Passalora concors (Casp.) U. Braun \& Crous & Dang & GEC 1996 \\
\hline & & Mycosphaerella berkeleyi W.A. Jenkins & Dang & GEC 1996 \\
\hline & & $\begin{array}{l}\text { Pseudocercospora subsessilis (Syd. \& P. Syd.) } \\
\text { Deighton }\end{array}$ & Dang & GEC 1996 \\
\hline & & Prathigada terminaliae (Syd.) B. Sutton & Dang, Junagadh, Panchmahal & GEC 1996 \\
\hline & & $\begin{array}{l}\text { Cercospora tridacis-procumbentis Thirum. \& } \\
\text { Govindu }\end{array}$ & Dang & GEC 1996 \\
\hline & & Pseudocercospora ziziphi (Petch) Crous \& U. Braun & Dang & GEC 1996 \\
\hline & & $\begin{array}{l}\text { Cercosporella tinosporae (Lacy \& Thirum.) } \\
\text { Deighton }\end{array}$ & Dang, Ratanamahal & GEC 1996 \\
\hline & & Septoria acanthospermi Sukapure \& Thirum. & Dang & GEC 1996 \\
\hline & & Septoria blainvilleae Sukapure \& Thirum. & Dang & GEC 1996 \\
\hline & & Septoria lactucae Pass. & Dang & GEC 1996 \\
\hline \multirow{2}{*}{ Diaporthales } & Diaporthaceae & Phomopsis phoenicicola Traverso \& Spessa & Ahmedabad & Gajjar et al. 2011 \\
\hline & & Phomopsis sp. & Anand & Yadav et al. 2013 \\
\hline \multirow[t]{4}{*}{ Meliolales } & Meliolaceae & Amazonia butleri (Syd. \& P. Syd.) F. Stevens & Dang & GEC 1996 \\
\hline & & Meliola palmicola $\mathrm{G}$. Winter & Dang & GEC 1996 \\
\hline & & Meliola sp. & Dang & GEC 1996 \\
\hline & & Meliola tamarindi Syd. \& P. Syd. & Dang & GEC 1996 \\
\hline Microthyriales & Microthyriaceae & Parmathyrites sp. & Kutch & Saxena \& Ranhotra 2009 \\
\hline \multirow[t]{5}{*}{ Pleosporales } & Pleosporaceae & Alternaria alternata (Fr.) Keissl. & Panchmahal, Dang & Nagadesi \& Arya, 2012 \\
\hline & & Alternaria burnsii Uppal, Patel \& Kamat & Dang, Junagadh & GEC 1996 \\
\hline & & Alternaria sp. & Anand, Kutch, Polo forest & $\begin{array}{l}\text { Shah et al. 2013; Yadav et al. 2013; } \\
\text { GSBTM } 2013\end{array}$ \\
\hline & & Alternaria tenuissima (Kunze) Wiltshire & Jessore, Polo forest, Patan & GSBTM 2013 \\
\hline & & $\begin{array}{l}\text { Curvularia ravenelii (M.A. Curtis ex Berk.) } \\
\text { Manamgoda, L. Cai \& K.D. Hyde }\end{array}$ & Dang & GEC 1996 \\
\hline
\end{tabular}




\begin{tabular}{|c|c|c|c|c|}
\hline Order & Family & Name of the species & Distribution & References \\
\hline & & Cochliobolus nodulosus Luttr. & Dang & GEC 1996 \\
\hline & & Curvularia hawaiiensis (Bugnic. ex M.B. Ellis) & Patan, Banaskantha & GSBTM-2013 \\
\hline & & Manamgoda, L. Cai \& K.D. Hyde & & \\
\hline & & Curvularia intermedia & Rajkot & Thaker et al. 2012 \\
\hline & & Curvularia lunata (Wakker) Boedijn & $\begin{array}{l}\text { Panchmahal, Dang, } \\
\text { Ratanmahal,Jessore }\end{array}$ & $\begin{array}{l}\text { Nagadesi \& Arya, 2012, GSBTM } \\
2013\end{array}$ \\
\hline & & Curvularia sp. & Jamnagar, Anand, Surat & $\begin{array}{l}\text { Katara et al. 2013; Shah et al. 2013; } \\
\text { Khokhar et al. } 2013\end{array}$ \\
\hline & & Helminthosporium sp. & Dang & GEC 1996 \\
\hline & & Paraphoma radicina (McAlpine) & Saputara & GSBTM-2013 \\
\hline & & $\begin{array}{l}\text { Phoma multirostrata (P.N. Mathur, S.K. } \\
\text { Menon \& Thirum.) Dorenb. \& Boerema }\end{array}$ & Panchmahal, Ratanmahal & Nagadesi \& Arya, 2012 \\
\hline & Venturiaceae & Fusicladium pongamiae & Dang & GEC 1996 \\
\hline \multirow[t]{15}{*}{ Eurotiales } & Trichocomaceae & Aspergillus awamori Nakaz. & Panchmahal & Nagadesi and Arya, 2012. \\
\hline & & Aspergillus caespitosus Raper \& Thom & Gandhinagar & GSBTM 2013 \\
\hline & & Aspergillus flavus Link & $\begin{array}{l}\text { Jamnagar, Surendranagar, Surat, } \\
\text { Panchmahal, Polo forest, Jessore, } \\
\text { Balaram, Gandhinagar }\end{array}$ & $\begin{array}{l}\text { Katara et al. 2013; Assudani et al. 2013; } \\
\text { Nasit et al. 2013; Panchal et al. 2013; } \\
\text { Khokhar et al. 2013; Nagadesi \& Arya, 2012 }\end{array}$ \\
\hline & & Aspergillus fruticulosus Raper \& Fennell & Jessore, Polo forest & GSBTM 2013 \\
\hline & & Aspergillus fumigatus Fresen. & $\begin{array}{l}\text { Jamnagar, Ahmedabad, Kutch, } \\
\text { Panchmahal, Gandhinagar, }\end{array}$ & $\begin{array}{l}\text { Katara et al. 2013; Panchal et al. } \\
\text { 2013; Nagadesi \& Arya, 2012; } \\
\text { GSBTM-2013 }\end{array}$ \\
\hline & & Aspergillus japonicas Saito & Gandhinagar, Balaram & GSBTM 2013 \\
\hline & & Aspergillus lentulus Balajee \& K.A. Marr & Jessore, Patan & GSBTM 2013 \\
\hline & & Aspergillus melleus Yukawa & Jessore & GSBTM 2013 \\
\hline & & Aspergillus multicolor Sappa & Junagadh & GSBTM 2013 \\
\hline & & $\begin{array}{l}\text { Aspergillus nomius Kurtzman, B.W. Horn \& } \\
\text { Hesselt }\end{array}$ & Godhra & GSBTM 2013 \\
\hline & & $\begin{array}{l}\text { Aspergillus brasiliensis Varga, Frisvad \& } \\
\text { Samson }\end{array}$ & $\begin{array}{lr}\text { Jamnagar, } & \text { Surendranagar, } \\
\text { Panchmahal, } & \text { Godhra, } \\
\text { Gandhinagar, } & \text { Junagadh, } \\
\text { Anand } & \end{array}$ & $\begin{array}{l}\text { Katara et al. 2013; Assudani et al. } \\
\text { 2013; Thaker et al. 2012; Panchal et } \\
\text { al. 2013; Nagadesi \& Arya, 2012, } \\
\text { Khan et al. } 2013\end{array}$ \\
\hline & & Aspergillus flavus Link & $\begin{array}{l}\text { Saputara, Kutch, Polo forest, } \\
\text { Gandhinagar }\end{array}$ & GSBTM 2013 \\
\hline & & $\begin{array}{l}\text { Aspergillus puniceus } \quad \text { Kwon-Chung \& } \\
\text { Fennell** }\end{array}$ & Polo forest & Present study \\
\hline & & Aspergillus sp. & $\begin{array}{l}\text { Kutch, Anand, Panchmahal, } \\
\text { Jessore }\end{array}$ & $\begin{array}{l}\text { Kumar et al. 2011; Shah et al. 2013; } \\
\text { Yadav et al. 2013; Nagadesi \& Arya, } \\
\text { 2012; GSBTM } 2013\end{array}$ \\
\hline & & Aspergillus terreus Thom & $\begin{array}{l}\text { Anand, Kutch, Waghai, Godhra, } \\
\text { Polo forest }\end{array}$ & Khan et al. 2013; GSBTM 2013 \\
\hline
\end{tabular}




\begin{tabular}{|c|c|c|c|c|}
\hline Order & Family & Name of the species & Distribution & References \\
\hline & & Aspergillus tubingensis Mosseray & Gandhinagar & GSBTM 2013 \\
\hline & & Aspergillus versicolor (Vuill.) Tirab. & $\begin{array}{l}\text { Anand, Kutch, Gandhinagar, } \\
\text { Patan, Jessore, Junagadh }\end{array}$ & Khan et al. 2013; GSBTM 2013 \\
\hline & & Aspergillus quadricinctus J.L. Yuill & Gandhinagar & GSBTM 2013 \\
\hline & & Emericella desertorum Samson \& Mouch. & Jessore & GSBTM 2013 \\
\hline & & Emericella nidulans (Eidam) Vuill. & Gandhinagar & GSBTM 2013 \\
\hline & & Emericella qinqixianii Y. Horie, Abliz \& R.Y. Li & Jessore & GSBTM 2013 \\
\hline & & Penicillium citrinum Thom & Jessore, Pavagadh & GSBTM 2013 \\
\hline & & $\begin{array}{l}\text { Talaromyces funiculosus (Thom) Samson, N. } \\
\text { Yilmaz, Frisvad \& Seifert }\end{array}$ & Anand & Yadav et al. 2013 \\
\hline & & Penicillium simplicissimum (Oudem.) Thom & Anand, Kutch & Khan et al. 2013,GSBTM 2013 \\
\hline & & Penicillium oxalicum Currie \& Thom & Junagadh, Rajkot, Jessore & GSBTM 2013 \\
\hline & & Penicillium sp. & Anand, Jessore & Shah et al. 2013; GSBTM 2013 \\
\hline & & $\begin{array}{l}\text { Talaromyces purpureogenus Samson, Yilmaz, } \\
\text { Houbraken, Spierenburg, Seifert, Peterson, } \\
\text { Varga \& Frisvad }\end{array}$ & Jessore & GSBTM 2013 \\
\hline & & Aspergillus amstelodami Thom \& Church & Kutch & GSBTM 2013 \\
\hline & & $\begin{array}{l}\text { Hamigera fusca S.W. Peterson, Jurjevic, Bills, } \\
\text { Stchigel, Guarro \& F.E. Vega }\end{array}$ & Kutch & GSBTM 2013 \\
\hline & & Merimbla ingelheimensis (J.F.H. Beyma) Pitt & Junagadh & GSBTM 2013 \\
\hline \multirow[t]{10}{*}{ Onygenales } & Arthrodermataceae & $\begin{array}{l}\text { Epidermophyton floccosum (Harz) Langeron \& } \\
\text { Miloch. }\end{array}$ & Karamsad, Surat & $\begin{array}{l}\text { Singh \& Beena, 2003; Bhavsar et al. } \\
2012\end{array}$ \\
\hline & & Epidermophyton $s p$ & Ahmedabad & Bhavsar et al. 2012 \\
\hline & & $\begin{array}{l}\text { Microsporum gypseum (E. Bodin) Guiart \& } \\
\text { Grigoraki }\end{array}$ & Ahmedabad & Nawal et al. 2012 \\
\hline & & Microsporum sp. & Ahmedabad & Bhavsar et al. 2012 \\
\hline & & $\begin{array}{l}\text { Trichophyton mentagrophytes (C.P. Robin) } \\
\text { Sabour }\end{array}$ & Surat, Ahmedabad, Karamsad & $\begin{array}{l}\text { Bhavsar et al. 2012; Nawal et al. } \\
\text { 2012; Singh \& Beena, } 2003\end{array}$ \\
\hline & & Trichophyton rubrum (Castell.) Sabour & Surat, Ahmedabad, Karamsad & $\begin{array}{l}\text { Bhavsar et al. 2012; Nawal et al. } \\
\text { 2012; Singh \& Beena, } 2003\end{array}$ \\
\hline & & $\begin{array}{l}\text { Trichophyton schoenleinii (Lebert) Langeron \& } \\
\text { Miloch. ex Nann. }\end{array}$ & Surat, Ahmedabad & Bhavsar et al. 2012 \\
\hline & & Trichophyton tonsurans Malmsten & Ahmedabad & Nawal et al. 2012 \\
\hline & & Trichophyton verrucosum $\mathrm{E}$. Bodin & Surat, Ahmedabad & Bhavsar et al. 2012 \\
\hline & & Trichophyton violaceum Sabour. ex E. Bodin & Surat, Ahmedabad, Karamsad & $\begin{array}{l}\text { Bhavsar et al. 2012; Nawal et al. } \\
\text { 2012; Singh \& Beena, } 2003\end{array}$ \\
\hline \multirow[t]{6}{*}{ Erysiphales } & Erysiphaceae & Erysiphe acaciae Erikss. & Dang & GEC 1996 \\
\hline & & Erysiphe polygoni DC. & Dang & GEC 1996 \\
\hline & & Leveillula taurica (Lév.) G. Arnaud & Dang & GEC 1996 \\
\hline & & Phyllactinia guttata (Wallr.) Lév. & Dang & GEC 1996 \\
\hline & & Phyllactinia subspiralis (E.S. Salmon) Sawada & Dang & GEC 1996 \\
\hline & & Erysiphe necator Schwein & Dang & GEC 1996 \\
\hline
\end{tabular}




\begin{tabular}{|c|c|c|c|c|}
\hline Order & Family & Name of the species & Distribution & References \\
\hline \multirow[t]{4}{*}{ Saccharomycetales } & Dipodascaceae & Geotrichum candidum Link & Anand & Khan et al. 2013 \\
\hline & Saccharomycetaceae & Candida albicans (C.P. Robin) Berkhout & Ahmedabad & Panchal et al. 2013 \\
\hline & & Candida sp. & Jamnagar, Surat, Ahmedabad & $\begin{array}{l}\text { Katara et al. 2013; Patel et al. 2010; } \\
\text { Bhavsar et al. 2012; Khokhar et al. } 2013\end{array}$ \\
\hline & & Candida tropicalis (Castell.) Berkhout & Ahmedabad, Dang & Panchal et al. 2013 \\
\hline \multirow[t]{5}{*}{ Glomerellales } & Glomerellaceae & Glomerella tucumanensis (Speg.) Arx \& E. & & \\
\hline & & Müll. & Dang, Pavagadh, & GEC 1996 \\
\hline & & $\begin{array}{l}\text { Colletotrichum gloeosporioides (Penz.) Penz. } \\
\& \text { Sacc. }\end{array}$ & Thol, Gandhinagar & GSBTM 2013 \\
\hline & & Colletotrichum graminicola (Ces.) G.W. Wilson & Dang, Ratanmahal & GEC 1996 \\
\hline & & Colletotrichum sp. & Anand & Yadav et al. 2013 \\
\hline \multirow[t]{22}{*}{ Hypocreales } & Bionectriaceae & Myrothecium roridum Tode & Balaram, Jessore & GSBTM 2013 \\
\hline & Clavicipitaceae & Balansia sclerotica (Pat.) Höhn. & Dang & GEC 1996 \\
\hline & Hypocreaceae & Trichoderma atroviride P. Karst. & Patan, Gandhinagar, Junagadh, & GSBTM 2013 \\
\hline & & Hypocrea muroiana I. Hino \& Katum. & Balaram & GSBTM 2013 \\
\hline & & Hypocrea sp. & Ahwa, Junagadh & GSBTM 2013 \\
\hline & & Trichoderma asperellum Lieckf. \& Nirenberg & Jessore, Patan, Bnaskantha & GSBTM 2013 \\
\hline & & Trichoderma citrinoviride Bissett & Godhra, Dang & GSBTM 2013 \\
\hline & & $\begin{array}{l}\text { Trichoderma erinaceum Bissett, C.P. Kubicek } \\
\& \text { Szakács }\end{array}$ & $\begin{array}{l}\text { Jessore, } \\
\text { Gandhinagar }\end{array}$ & GSBTM 2013 \\
\hline & & Trichoderma harzianum Rifai & $\begin{array}{l}\text { Panchmahal, } \quad \text { Jessore, } \\
\text { Junagadh }\end{array}$ & $\begin{array}{l}\text { Nagadesi \& Arya, 2012; GSBTM } \\
2013\end{array}$ \\
\hline & & $\begin{array}{l}\text { Trichoderma koningiopsis Samuels, C. Suárez } \\
\text { \& H.C. Evans }\end{array}$ & Godhra, Pavagadh, Jessore & GSBTM 2013 \\
\hline & & Trichoderma longibrachiatum Rifai & $\begin{array}{l}\text { Jessore, Junagadh, Balaram, } \\
\text { Gandhinagar }\end{array}$ & GSBTM 2013 \\
\hline & & Trichoderma sp. & $\begin{array}{l}\text { Panchmahal, Waghai, Ahwa, } \\
\text { Junagadh, Godhra }\end{array}$ & $\begin{array}{l}\text { Nagadesi \& Arya, 2012; GSBTM } \\
2013\end{array}$ \\
\hline & & Trichoderma viride Pers. & $\begin{array}{l}\text { Panchmahal, Thol, Dang, } \\
\text { Ratanmahal }\end{array}$ & $\begin{array}{l}\text { Nagadesi \& Arya, 2012, GSBTM } \\
2013\end{array}$ \\
\hline & & $\begin{array}{l}\text { Trichoderma viridescens (A.S. Horne \& H.S. } \\
\text { Will.) Jaklitsch \& Samuels }\end{array}$ & Godhra & GSBTM 2013 \\
\hline & Nectriaceae & Fusarium brachygibbosum Padwick & Thol & GSBTM 2013 \\
\hline & & Gibberella intricans Wollenw. & Polo forest, Jessore, Saputara & GSBTM 2013 \\
\hline & & Fusarium fujikuroi Nirenberg & Godhra & GSBTM 2013 \\
\hline & & Fusarium incarnatum (Desm.) Sacc. & Junagadh & GSBTM 2013 \\
\hline & & Gibberella baccata (Wallr.) Sacc. & Gandhinagar & GSBTM 2013 \\
\hline & & Fusarium oxysporum E.F. Sm. \& Swingle & Anand, Panchmahal & Khan et al. 2013; Nagadesi \& Arya, 2012 \\
\hline & & Fusarium pallidoroseum (Cooke) Sacc. & Panchmahal & Nagadesi \& Arya, 2012 \\
\hline & & $\begin{array}{l}\text { Fusarium proliferatum (Matsush.) Nirenberg } \\
\text { ex Gerlach \& Nirenberg }\end{array}$ & Godhra & GSBTM 2013 \\
\hline
\end{tabular}




\begin{tabular}{|c|c|c|c|c|}
\hline Order & Family & Name of the species & Distribution & References \\
\hline & & $\begin{array}{l}\text { Haematonectria haematococca } \\
\text { Broome) Samuels \& Rossman }\end{array}$ & Thol, Junagadh, Gandhinagar & GSBTM 2013 \\
\hline & & Fusarium sp. & Rajkot, Junagadh & $\begin{array}{l}\text { Katara et al. 2013; Kumar et al. 2011; } \\
\text { Shah et al. 2013; Thaker et al. 2012; } \\
\text { GSBTM 2013. }\end{array}$ \\
\hline & & Gibberella intermedia (Kuhlmann) & Godhra & GSBTM 2013 \\
\hline & & $\begin{array}{l}\text { Gliocephalotrichum simplex (J.A. Mey.) B.J. } \\
\text { Wiley \& E.G. Simmons }\end{array}$ & Junagadh & GSBTM 2013 \\
\hline Microascales & Ceratocystidaceae & Ceratocystis paradoxa (Dade) C. Moreau & Panchmahal & Nagadesi \& Arya, 2012 \\
\hline \multirow{2}{*}{ Phyllachorales } & Phyllachoraceae & Phyllachora cynodontis Niessl & Dang & GEC 1996 \\
\hline & & Phyllachora yapensis (Henn.) Syd. \& P. Syd. & Dang & GEC 1996 \\
\hline \multirow[t]{5}{*}{ Sordariales } & Chaetomiaceae & Chaetomium atrobrunneum L.M. Ames & Thol & GSBTM 2013 \\
\hline & & Chaetomium brasiliense Bat. \& Pontual & $\begin{array}{l}\text { Thol, Kutch, Waghai, } \\
\text { Junagadh }\end{array}$ & GSBTM 2013 \\
\hline & & Chaetomium globosum Kunze & $\begin{array}{l}\text { Panchmahal, } \\
\text { Ratanmahal }\end{array}$ & Nagadesi \& Arya, 2012 \\
\hline & & $\begin{array}{l}\text { Corynascus kuwaitiensis Z.U. Khan \& Suh. } \\
\text { Ahmad }\end{array}$ & Junagadh & GSBTM 2013 \\
\hline & Sordariaceae & Neurospora sp. & Anand & Shah et al. 2013 \\
\hline \multirow[t]{2}{*}{ Taphrinales } & Taphrinaceae & Taphrina maculans E.J. Butler & Dang & GEC 1996 \\
\hline & & Taphrina rhomboidalis P. Syd. \& E.J. Butler & Dang & GEC 1996 \\
\hline \multirow[t]{2}{*}{ Trichosphaeriales } & Trichospariaceae & Nigrospora sp. & Gandhinagar, Junagadh & GSBTM 2013 \\
\hline & & Nigrospora sphaerica Khuskia oryzae H.J. Huds. & Junagadh & GSBTM 2013 \\
\hline \multirow[t]{9}{*}{ Xylariales } & Amphisphaeriaceae & Pestalotiopsis sp.. & Panchmahal & Nagadesi \& Arya, 2012 \\
\hline & Diatrypaceae & Eutypa sp. & Polo forest, Patan & GSBTM 2013 \\
\hline & Xylariaceae & Daldinia childiae J.D. Rogers \& Y.M. Ju & Panchmahal, Dang, Junagadh & Korat et al. 2013 \\
\hline & & Daldinia eschscholzii (Ehrenb.) Rehm & $\begin{array}{l}\text { Gandhinagar, Junagadh, Polo } \\
\text { forest, Saputara }\end{array}$ & GSBTM 2013 \\
\hline & & Hypoxylon begae Y.M. Ju \& J.D. Rogers & Junagadh, Dang & GSBTM 2013 \\
\hline & & Hypoxylon fragiforme (Pers.) J. Kickx f. & Junagadh, Rajpipla, Dang & GSBTM 2013 \\
\hline & & Xylaria feejeensis (Berk.) Fr. & Gandhinagar, Baroda, Dang & GSBTM 2013 \\
\hline & & Xylaria regalis Cooke & Junagadh, Dang & GSBTM 2013 \\
\hline & & Xylaria sp. & Junagadh & GSBTM 2013 \\
\hline \multicolumn{5}{|l|}{ BASIDIOMYCOTA } \\
\hline \multirow[t]{6}{*}{ Agaricales } & Agaricaceae & Agaricus blazei Murrill & Thol, Ratanmahal & GSBTM 2013 \\
\hline & & Agaricus bisporus (J.E. Lange) Imbach & Navsari & Korat et al. 2013; GSBTM 2013 \\
\hline & & Agaricus goossensiae Heinem. & Thol & GSBTM 2013 \\
\hline & & Agaricus silvaticus Schaeff.** & Baroda & \\
\hline & & Cystolepiota oregonensis (H.V. Sm.) Vellinga & Navsari & Korat et al. 2013; GSBTM 2013 \\
\hline & & $\begin{array}{l}\text { Leucoagaricus vassiljevae E.F. Malysheva, } \\
\text { T.Yu. Svetasheva \& E.M. Bulakh }\end{array}$ & Thol & GSBTM 2013 \\
\hline
\end{tabular}




\begin{tabular}{|c|c|c|c|c|}
\hline Order & Family & Name of the species & Distribution & References \\
\hline & & Podaxis pistillaris (L.) Fr. & Gandhinagar, Waghai & GSBTM 2013 \\
\hline & Pluteaceae & Pluteus cervinus (Schaeff.) P. Kumm.** & Dang, Baroda & \\
\hline & Cortinariaceae & Galerina praticola (F.H. Møller) P.D. Orton & Navasari & Korat et al. 2013 \\
\hline & Clavariaceae & Clavaria rosea Dalman $* *$ & Jambughoda, Dharampur & \\
\hline & Inocybaceae & Crepidotus fimbriatus Hesler \& A.H. Sm.** & Ratanmahal & \\
\hline & Hygrophoraceae & Hygrophorus eburneus (Bull.) Fr. & Navsari & Korat et al. 2013 \\
\hline & \multirow[t]{2}{*}{ Lycoperdaceae } & Lycoperdon pyriforme Schaeff. & Navsari & Korat et al. 2013 \\
\hline & & Calocybe indica Purkay. \& A. Chandra & $\begin{array}{l}\text { Polo forest, Waghai, } \\
\text { Gandhinagar, Thol }\end{array}$ & GSBTM 2013 \\
\hline & Marasmiaceae & $\begin{array}{l}\text { Marasmius albimyceliosus Corner } \\
\text { Gerronema subclavatum (Peck) Singer ex } \\
\text { Redhead** }\end{array}$ & $\begin{array}{l}\text { Gandhinagar. } \\
\text { Dharampur }\end{array}$ & GSBTM 2013 \\
\hline & Mycenaceae & Mycena sp. & Waghai & GSBTM 2013 \\
\hline & \multirow{2}{*}{ Phelloriniaceae } & Phellorinia herculeana (Pers.) Kreisel & Gandhinagar, Junagadh & GSBTM 2013 \\
\hline & & Hymenopellis colensoi (Dörfelt) R.H. Petersen & Navsari & Korat et al. 2013 \\
\hline & \multirow[t]{2}{*}{ Pleurotaceae } & Pleurotus cornucopiae (Paulet) Rolland & Gandhinagar,Dang & GSBTM 2013 \\
\hline & & Pleurotus pulmonarius (Fr.) Quél. & Ahmedabad, Junagadh, Dang & GSBTM 2013 \\
\hline & \multirow[t]{4}{*}{ Psathyrellaceae } & $\begin{array}{l}\text { Coprinellus micaceus (Bull.) Vilgalys, Hopple } \\
\text { \& Jacq. Johnson }\end{array}$ & Thol, Dang & GSBTM 2013 \\
\hline & & $\begin{array}{l}\text { Coprinellus xanthothrix (Romagn.) Vilgalys, } \\
\text { Hopple \& Jacq. Johnson }\end{array}$ & Gandhinagar & GSBTM 2013 \\
\hline & & $\begin{array}{l}\text { Parasola plicatilis (Curtis) Redhead, Vilgalys } \\
\text { \& Hopple** }\end{array}$ & Ratanmahal & \\
\hline & & $\begin{array}{l}\text { Coprinopsis cinerea (Schaeff.) Redhead, } \\
\text { Vilgalys \& Moncalvo }\end{array}$ & Gandhinagar & GSBTM 2013 \\
\hline & Schizophyllaceae & Schizophyllum commune Fr. & $\begin{array}{l}\text { Navsari, Ratanmahal, Jessore, } \\
\text { Rajpipla, } \quad \text { Gandhinagar, } \\
\text { Junagadh, Waghai, Ahwa, }\end{array}$ & $\begin{array}{l}\text { Korat et al. 2013; Nagadesi \& Arya, } \\
\text { 2012, 2013; GSBTM } 2013\end{array}$ \\
\hline & Strophariaceae & Galerina praticola (F.H. Møller) P.D. Orton & Navsari & Korat et al. 2013 \\
\hline & \multirow[t]{6}{*}{ Tricholomataceae } & Cantharellula umbonata (J.F. Gmel.) Singer & Navsari & Korat et al. 2013 \\
\hline & & Clitocybe bresadolana Singer & Navsari & Korat et al. 2013 \\
\hline & & Collybia butyracea (Bull.) P. Kumm. & Navsari & Korat et al. 2013 \\
\hline & & $\begin{array}{l}\text { Neolentinus kauffmanii (A.H. Sm.) Redhead } \\
\text { \& Ginns }\end{array}$ & Polo forest & GSBTM 2013 \\
\hline & & Macrocybe gigantea (Massee) Pegler \& Lodge & Gandhinagar, Junagadh & GSBTM 2013 \\
\hline & & $\begin{array}{l}\text { Tricholosporum porphyrophyllum (S. Imai) } \\
\text { Guzmán ex T.J. Baroni }\end{array}$ & Thol & GSBTM 2013 \\
\hline Atheliales & Atheliaceae & Athelia rolfsii (Curzi) C.C. Tu \& Kimbr. & Junagadh & Kumar et al. 2013 \\
\hline \multirow[t]{2}{*}{ Auriculariales } & Auriculariaceae & Auricularia cornea Ehrenb.** & Ratanmahal, Junagadh & \\
\hline & & $\begin{array}{l}\text { Auricularia nigricans (Fr.) Birkebak, Looney } \\
\text { \& Sánchez-García** }\end{array}$ & Junagadh, Pavgadh,Dang & \\
\hline
\end{tabular}




\begin{tabular}{|c|c|c|c|c|}
\hline Order & Family & Name of the species & Distribution & References \\
\hline Boletales & Sclerodermataceae & Scleroderma citrinum Pers. & Navsari & Korat et al. 2013 \\
\hline Gomphales & Gomphaceae & Ramaria formosa (Pers.) Quél.** & Jambughoda, Junagadh & \\
\hline Gloeophyllales & Gloeophyllaceae & Gloeophyllum sepiarium (Wulfen) P. Karst. & Rajpipla & Nagadesi \& Arya 2013 \\
\hline \multirow[t]{15}{*}{ Hymenochaetales } & Hymenochaetaceae & Phellinus fastuosus (Lév.) S. Ahmad & Gandhinagar, Godhra & GSBTM 2013 \\
\hline & & Inocutis porrecta (Murrill) Baltazar & Gandhinagar & GSBTM 2013 \\
\hline & & Phellinus badius (Cooke) G. Cunn. & Vadia palace, Rajpipla & Nagadesi \& Arya 2013 \\
\hline & & Phellinus caryophylli (Racib.) G. Cunn. & Vadia palace, Rajpipla & Nagadesi \& Arya 2013 \\
\hline & & Phellinus conchatus (Pers.) Quél. & Vadia palace, Rajpipla & Nagadesi \& Arya 2013 \\
\hline & & Phellinus hoehnelii (Bres.) Ryvarden & Vadia palace, Rajpipla & Nagadesi \& Arya 2013 \\
\hline & & Phellinus nilgheriensis (Mont.) G. Cunn. & Ratanmahal & $\begin{array}{l}\text { Arya et al. 2008; } \\
\text { Nagadesi \& Arya, } 2012\end{array}$ \\
\hline & & Phellinus dingleyae P.K. Buchanan \& Ryvarden & Vadia palace, Rajpipla & Nagadesi \& Arya 2013 \\
\hline & & Phylloporia pectinata (Klotzsch) Ryvarden & Vadia palace, Rajpipla & Nagadesi \& Arya 2013 \\
\hline & & $\begin{array}{l}\text { Fuscoporia rhabarbarina (Berk.) Groposo, } \\
\text { Log.-Leite \& Góes-Neto }\end{array}$ & Vadia palace, Rajpipla & Nagadesi \& Arya 2013 \\
\hline & & Phylloporia ribis (Schumach.) Ryvarden & Thol & GSBTM 2013 \\
\hline & & Fomitiporia robusta (P. Karst.) Fiasson \& Niemelä & Vadia palace, Rajpipla, Pavagdh, Dang & Nagadesi \& Arya 2013 \\
\hline & & $\begin{array}{l}\text { Fuscoporia senex (Nees \& Mont.) Ghob.- } \\
\text { Nejh. }\end{array}$ & Thol & GSBTM 2013 \\
\hline & & $\begin{array}{l}\text { Phellinus setulosu Fuscoporia wahlbergii (Fr.) } \\
\text { T. Wagner \& M. Fisch. }\end{array}$ & Vadia palace, Rajpipla & Nagadesi \& Arya 2013 \\
\hline & & Phellinus sp. & Ratanmahal & Nagadesi \& Arya, 2012 \\
\hline \multirow[t]{12}{*}{ Polyporales } & Fomitopsidaceae & $\begin{array}{l}\text { Antrodia sitchensis (D.V. Baxter) Gilb. \& } \\
\text { Ryvarden }\end{array}$ & Rajkot & Thaker et al. 2012 \\
\hline & & Fomitopsis Africana Mossebo \& Ryvarden & $\begin{array}{l}\text { Godhra, Gandhinagar, Junagadh, } \\
\text { Polo forest }\end{array}$ & GSBTM 2013 \\
\hline & & Fomes meliae (Underw.) Murrill & Thol & GSBTM 2013 \\
\hline & & Laetiporus sulphureus (Bull.) Murrill & Navsari & Korat et al. 2013 \\
\hline & Ganodermataceae & Ganoderma sp. & Gandhinagar & GSBTM 2013 \\
\hline & & Ganoderma annulare & Gandhinagar & GSBTM 2013 \\
\hline & & Ganoderma australe (Fr.) Pat. & Gandhinagar, Dang, Junagadh & GSBTM 2013 \\
\hline & & Ganoderma orbiforme (Fr.) Ryvarden & Thol, Ratanmahal, Navsari & $\begin{array}{l}\text { Korat et al. 2013; GSBTM 2013; } \\
\text { Nagadesi \& Arya; 2012, }\end{array}$ \\
\hline & & Ganoderma multipileum Ding Hou & $\begin{array}{l}\text { Gandhinagar, Waghai, Junagadh, } \\
\text { Polo forest, Thol }\end{array}$ & GSBTM 2013 \\
\hline & Meruliaceae & $\begin{array}{l}\text { Ganoderma applanatum (Pers.) Pat. (1887) } \\
\text { Flavodon flavus (Klotzsch) Ryvarden }\end{array}$ & $\begin{array}{l}\text { Navsari, Baroda ,Dang, Junagadh } \\
\text { Rajpipla, Ratanmahal, Godhra, } \\
\text { Gandhinagar, Waghai, Junagadh }\end{array}$ & $\begin{array}{l}\text { Chandulal et al. } \\
\text { Nagadesi et al. 2013; Nagadesi \& } \\
\text { Arya, 2012, GSBTM } 2013\end{array}$ \\
\hline & & Podoscypha petalodes (Berk.) Boidin & Gandhinagar, Rajpipla & GSBTM 2013 \\
\hline & Polyporaceae & Trametes versicolor (L.) Lloyd & Navsari, Ratanmahal & $\begin{array}{l}\text { Korat et al. 2013, } \\
\text { Nagadesi \& Arya, } 2012\end{array}$ \\
\hline
\end{tabular}




\begin{tabular}{|c|c|c|c|c|}
\hline Order & Family & Name of the species & Distribution & References \\
\hline & & $\begin{array}{l}\text { Funalia caperata } \\
\text { Malysheva }\end{array}$ & Gandhinagar, Ahwa, Junagadh & GSBTM 2013 \\
\hline & & $\begin{array}{l}\text { Funalia aspera (Jungh.) Zmitr. \& V. } \\
\text { Malysheva }\end{array}$ & Ratanmahal,Dang & Arya et al. 2008 \\
\hline & & Daedalea flavida Lév.** & Junagadh & \\
\hline & & Dichomitus squalens (P. Karst.) D.A. Reid & Junagadh & GSBTM 2013 \\
\hline & & Earliella scabrosa (Pers.) Gilb. \& Ryvarden & Junagadh & GSBTM 2013 \\
\hline & & $\begin{array}{l}\text { Trametes apiaria (Pers.) Zmitr., Wasser \& } \\
\text { Ezhov }\end{array}$ & Ratanmahal, Vijaynagar & $\begin{array}{l}\text { Arya et al. 2008; Nagadesi \& Arya } \\
2012,2013\end{array}$ \\
\hline & & $\begin{array}{l}\text { Daedaleopsis nitida (Durieu \& Mont.) Zmitr. } \\
\& \text { V. Malysheva** }\end{array}$ & Dharampur, Ratanmhal & \\
\hline & & Hexagonia tenuis Speg. & Ratanmahal, Dang & Nagadesi \& Arya 2012, 2013 \\
\hline & & Microporus vernicipes (Berk.) Kuntze & Waghai, Saputara, Junagadh & GSBTM 2013 \\
\hline & & Microporus xanthopus (Fr.) Kuntze & Junagadh, Pavagdh & \\
\hline & & $\begin{array}{l}\text { Microporus ochrotinctus (Berk. \& M.A. } \\
\text { Curtis) Kuntze }\end{array}$ & Gandhinagar, Junagadh & GSBTM 2013 \\
\hline & & Navisporus floccosus (Bres.) Ryvarden & Ratanmahal & $\begin{array}{l}\text { Arya et al. 2008; Nagadesi \& Arya } \\
2012,2013\end{array}$ \\
\hline & & Polyporus tricholoma Mont. & Gandhinagar, Rajpipla, Dang & GSBTM 2013 \\
\hline & & Polyporus arcularius Rostk.** & Dangs, Ratanmahal & \\
\hline & & Trametes ljubarskyi Pilát & Gandhinagar & GSBTM 2013 \\
\hline & & Lenzites betulina (L.) Fr. & Ratanmahal, Junagadh & Nagadesi \& Arya, 2012 \\
\hline & & Lenzites eximia Berk. \& M.A. Curtis & Ratanmahal, Rajpipla & Nagadesi \& Arya, 2012 \\
\hline & & Lenzites stereoides (Fr.) Ryvarden & Ratanmahal, Dang & $\begin{array}{l}\text { Arya et al. 2008, Nagadesi \& Arya } \\
2012,2013 \text {, }\end{array}$ \\
\hline & & Lenzites sp. & Waghai, Ahwa, Saputara & GSBTM 2013 \\
\hline & & $\begin{array}{l}\text { Antrodia malicola (Berk. \& M.A. Curtis) } \\
\text { Donk }\end{array}$ & Ratanmahal & Arya et al. 2008 \\
\hline & & Trametes lactinea (Berk.) Sacc. & Ratanmahal & Arya et al. 2008 \\
\hline & & Trametes sp. & Ratanmahal & Nagadesi \& Arya,2012 \\
\hline & & Trametes pini (Brot.) Fr. & Ratanmahal & Nagadesi \& Arya, 2012 \\
\hline & & Trametes hirsute (Wulfen) Lloyd $* *$ & Junagadh & Present study \\
\hline & & Trametes versicolor (L.) Lloy, ** & Junagadh & \\
\hline & & Trametes ljubarskyi Pilát** & Junagadh & \\
\hline & Sparassidaceae & Sparassis crispa (Wulfen) Fr, ** & Waghai & \\
\hline Russulales & Auriscalpiaceae & Lentinellus cochleatus (Pers.) P. Karst. & Navsari & Korat et al. 2013 \\
\hline & Bondarzewiaceae & Amylosporus campbellii Berk.) Ryvarden & Gandhinagar, Junagadh & GSBTM 2013 \\
\hline & & Bondarzewia berkeleyi (Fr.) Bondartsev \& Singer & Ratanmahal & Nagadesi \& Arya, 2012, 2013 \\
\hline Dacrymycetales & Dacrymycetaceae & $\begin{array}{l}\text { Dacryopinax spathularia (Schwein.) G.W. } \\
\text { Martin** }\end{array}$ & Dang, Junagadh, Ratanmahal & \\
\hline
\end{tabular}




\begin{tabular}{|c|c|c|c|c|}
\hline Order & Family & Name of the species & Distribution & References \\
\hline Doassansiales & Doassansiaceae & $\begin{array}{l}\text { Heterodoassansia hygrophilae (Thirum.) } \\
\text { Vánky }\end{array}$ & Dang & GSBTM 2013 \\
\hline Georgefischeriales & Eballistraceae & $\begin{array}{l}\text { Eballistra brachiariae (Viégas) R. Bauer, } \\
\text { Begerow, A. Nagler \& Oberw }\end{array}$ & Dang & GSBTM 2013 \\
\hline Entylomatales & Entylomataceae & $\begin{array}{l}\text { Entyloma bidentis Speg. } \\
\text { Eballistra oryzae (Syd. \& P. Syd.) R. Bauer, } \\
\text { Begerow, A. Nagler \& Oberw. }\end{array}$ & $\begin{array}{l}\text { Dang } \\
\text { Dang }\end{array}$ & $\begin{array}{l}\text { GEC } 1996 \\
\text { GEC } 1996\end{array}$ \\
\hline \multirow[t]{7}{*}{ Microbotryales } & Microbotryaceae & $\begin{array}{l}\text { Microbotryum emodensis (Berk.) M. } \\
\text { Piepenbr. }\end{array}$ & Dang & GEC 1996 \\
\hline & & $\begin{array}{l}\text { Sphacelotheca erythraeensis (Syd. \& P. Syd.) } \\
\text { G.P. Clinton }\end{array}$ & Dang & GEC 1996 \\
\hline & & Sporisorium isachnes (Syd. \& P. Syd.) Vánky & Dang & GEC 1996 \\
\hline & & $\begin{array}{l}\text { Sporisorium iseilematis (Syd., P. Syd. \& E.J. } \\
\text { Butler) Vánky }\end{array}$ & Dang & GEC 1996 \\
\hline & & Sporisorium cruentum (J.G. Kühn) Vánky & Dang & GEC 1996 \\
\hline & & Sporisorium sorghi Ehrenb. ex Link & Dang & GEC 1996 \\
\hline & & $\begin{array}{l}\text { Sporisorium tanglinense (Tracy \& Earle) L. } \\
\text { Guo }\end{array}$ & Dang & GEC 1996 \\
\hline \multirow[t]{21}{*}{ Pucciniales } & Chaconiaceae & Acervulopsora ichnocarpi Thirum. & Dang & GEC 1996 \\
\hline & & Chaconia butleri (Syd. \& P. Syd.) Mains & Dang & GEC 1996 \\
\hline & & Maravalia aulica (Syd.) Y. Ono & Dang & GEC 1996 \\
\hline & Phakopsoraceae & Kweilingia divina (Syd.) Buriticá & Dang & GEC 1996 \\
\hline & & $\begin{array}{l}\text { Uredopeltis chevalieri J. Walker \& R.G. } \\
\text { Shivas }\end{array}$ & Dang & GEC 1996 \\
\hline & & $\begin{array}{l}\text { Kuehneola flacourtiae (Mundk. \& Thirum.) } \\
\text { Thirum. }\end{array}$ & Dang & GEC 1996 \\
\hline & & Phragmidiella sp. & Kutch & Saxena \& Ranhotra. 2009 \\
\hline & Pucciniaceae & Puccinia cacao McAlpine & Dang & GEC 1996 \\
\hline & & Puccinia cynodontis Lacroix ex Desm. & Dang & GEC 1996 \\
\hline & & Puccinia duthiae Van der Byl & Dang & GEC 1996 \\
\hline & & Puccinia substriata Ellis \& Barthol. & Dang & GEC 1996 \\
\hline & & Puccinia prainiana Barclay & Dang & GEC 1996 \\
\hline & & Puccinia purpurea Cooke & Dang & GEC 1996 \\
\hline & & Puccinia ruelliae Lagerh. & Dang & GEC 1996 \\
\hline & & Puccinia versicolor Dietel \& Holw. & Dang & GEC 1996 \\
\hline & & Puccinia wattiana Barclay & Dang & GEC 1996 \\
\hline & & Trochodium ajrekari Gharse & Dang & GEC 1996 \\
\hline & & Trochodium sampathense Thirum. & Dang & GEC 1996 \\
\hline & & Uromyces appendiculatus F. Strauss & Dang & GEC 1996 \\
\hline & & Uromyces clignyi Pat. \& Har. & Dang & GEC 1996 \\
\hline & & Uromyces hobsoni Vize & Dang & GEC 1996 \\
\hline
\end{tabular}




\begin{tabular}{|c|c|c|c|c|}
\hline Order & Family & Name of the species & Distribution & References \\
\hline & & Uromyces inayati Syd. \& P. Syd. & Dang & GEC 1996 \\
\hline & & Uromyces mucunae Rabenh. & Dang, Junagadh & GEC 1996 \\
\hline & & Uromyces orientalis Syd. \& P. Syd. & Dang & GEC 1996 \\
\hline & & Uromyces setariae-italicae Yoshino & Dang & GEC 1996 \\
\hline & Raveneliaceae & $\begin{array}{l}\text { Hapalophragmium ponderosum Syd, P. Syd. } \\
\text { \& E.J. Butler }\end{array}$ & Dang & GEC 1996 \\
\hline & & $\begin{array}{l}\text { Ravenelia acaciae-arabicae Mundk. \& } \\
\text { Thirum. }\end{array}$ & Dang & GEC 1996 \\
\hline & & Ravenelia albizziae-amarae Bacc. & Dang & GEC 1996 \\
\hline & & Ravenelia hobsoni Cooke & Dang & GEC 1996 \\
\hline & & Ravenelia ornata Syd. \& P. Syd. & Dang & GEC 1996 \\
\hline \multirow[t]{3}{*}{ Tremellales } & Aporpiaceae & Elmerina dimidiata (A. David) D.A. Reid & Ahwa & GSBTM 2013 \\
\hline & Tremellaceae & Tremella foliacea Pers. $* *$ & Dang, Junagadh & \\
\hline & & Tremella mesenterica Retz. ** & Panchmahal, Junagadh & \\
\hline \multirow[t]{14}{*}{ Ustilaginales } & Anthracoideaceae & $\begin{array}{l}\text { Anthracocystis ehrenbergii (J.G. Kühn) } \\
\text { McTaggart \& R.G. Shivas }\end{array}$ & Dang & GEC 1996 \\
\hline & Glomosporiaceae & $\begin{array}{l}\text { Anthracocystis formosana } \\
\text { McTaggart \& R.G. Shivas }\end{array}$ & Dang & GEC 1996 \\
\hline & & $\begin{array}{l}\text { Anthracocystis heteropogonicola (Mundk. \& } \\
\text { Thirum.) McTaggart \& R.G. Shivas }\end{array}$ & Dang & GEC 1996 \\
\hline & & Sorosporium paspali McAlpine & Dang & GEC 1996 \\
\hline & Ustilaginaceae & Cintractia axicola (Berk.) Cornu & Dang & GEC 1996 \\
\hline & & $\begin{array}{l}\text { Melanopsichium eleusines (Kulk.) Mundk. \& } \\
\text { Thirum. }\end{array}$ & Dang & GEC 1996 \\
\hline & & Melanopsichium pennsylvanicum Hirschh. & Dang & GEC 1996 \\
\hline & & Pericladium grewiae Pass. & Dang & GEC 1996 \\
\hline & & Ustilago crameri Körn. & Dang & GEC 1996 \\
\hline & & Ustilago cynodontis (Pass.) Henn. & Dang & GEC 1996 \\
\hline & & Ustilago maydis (DC.) Corda & Dang & GEC 1996 \\
\hline & & Ustilago crus-galli Tracy \& Earle & Dang & GEC 1996 \\
\hline & & $\begin{array}{l}\text { Sporisorium scitamineum (Syd.) M. Piepenbr., } \\
\text { M. Stoll \& Oberw. }\end{array}$ & Dang & GEC 1996 \\
\hline & & Ustilago sparsa Underw. & Dang & GEC 1996 \\
\hline \multicolumn{5}{|c|}{ CHYTRIDIOMYCOTA } \\
\hline \multirow[t]{3}{*}{ Blastocladiales } & Physodermataceae & $\begin{array}{l}\text { Physoderma aeschynomenis Thirum. \& M.D. } \\
\text { Whitehead }\end{array}$ & Dang & GEC 1996 \\
\hline & & $\begin{array}{l}\text { Physoderma echinochloae Thirum. \& M.D. } \\
\text { Whitehead }\end{array}$ & Dang & GEC 1996 \\
\hline & & Physoderma zeae-maydis F.J.F. Shaw & Dang & GEC 1996 \\
\hline Chytridiales & Synchytriaceae & Woroninella puerariae (Henn.) Syd. & Dang & GEC 1996 \\
\hline
\end{tabular}




\begin{tabular}{|c|c|c|c|c|}
\hline Order & Family & Name of the species & Distribution & References \\
\hline \multicolumn{5}{|c|}{ "ZYGOMYCOTA" } \\
\hline \multirow[t]{8}{*}{ Mucorales } & Mucoraceae & Absidia sp. & Ratanmahal & Nagadesi \& Arya, 2012 \\
\hline & & $\begin{array}{l}\text { Mucor irregularis Stchigel, Cano, Guarro \& } \\
\text { Ed. Álvarez }\end{array}$ & Polo, Waghai & GSBTM 2013 \\
\hline & & Mucor racemosus Bull. & Ratanmahal, Dang, Jessore & Nagadesi \& Arya, 2012 \\
\hline & & Mucor sp. & Anand & Shah et al. 2013 \\
\hline & & Rhizopus arrhizus A. Fisch. & Godhra, Ratanmahal, Dang & GSBTM 2013 \\
\hline & & Rhizopus sp. & Ratanmahal & Nagadesi \& Arya ,2012 \\
\hline & & Rhizopus stolonifer (Ehrenb.) Vuill. & Ratanmahal, Dang & Nagadesi \& Arya, 2012 \\
\hline & & Helicocephalum sp. & Ratanmahal & Nagadesi \& Arya, 2012 \\
\hline
\end{tabular}

\section{Result \& Discussion}

Table 1 list 334 species of 158 genera on the basis of available literature and our own collections (Figure 1-6) from different biogeographic regions of Gujarat. The list is arranged according to Webster and Weber (2007) except the species belonging to "Zygomycota" which is kept as a group with uncertain position. It includes 78 families comprising 59 genera of Ascomycota, 85 genera of Basidiomycota, 3 genera of Chytridiomycota, 3 genera of Oomycota, 4 genera of "Zygomycota" and 5 genera belonging to Myxomyota. A perusal of the literature indicates that most of the studies on fungal diversity of Gujarat are recent while earlier studies are very few or almost nil. Most of these studies are published in journals having restricted distribution and limited availability.

The 341 species listed here include 98 species of our own collection and 243 species from previous data. At the family level, Polyporaceae has the largest number of species (12 genera: 25 species) followed by Trichocomaceae (6 genera: 28 species) and Pucciniaceae (3 genera: 18 species). The most represented genera are Aspergillus, Ganoderma, Microporus, Dictyophora, Flavodon, Schizophyllum, Coprinus, Daldinia, Polyporus, Xylaria and Auricularia. It has to be emphasized that this list is a very preliminary one revealing only a small part of the total fungal diversity of the state.

\section{Acknowledgements}

Authors are thankful to Prof. (Dr.) K. D. Hyde (Editor in Chief) and anonymous reviewers for their critical comments on the manuscript. Financial assistance by the Gujarat Biodiversity Board is gratefully acknowledged.

\section{References}

Arya A, Albert S, Nagdesi PK. 2008 - New and interesting records of Basidiomycetous fungi from Ratanmahal Wildlife Sanctuary, Gujarat, India. Mycology and Plant Pathology 38, 221-226.

Assudani HJ, Pandya JM, Sarvan RR, Sapre AM, Gupta AR, Mehta SJ. 2013 - Etiological diagnosis of microbial keratitis in a tertiary care hospital in Gujarat. National Journal of Medical Research 3, 60-62.

Bhavsar HK, Modi DJ, Sood NK, Shah H. 2012 - A study of superficial mycoses with clinical mycological profile in tertiary care hospital in Ahmedabad, Gujarat. National Journal of Medical Research 2(2), 160-164.

Champion HG, Seth SK. 1968 - A Revised Survey of Forest Types of India, Govt. of India Press, New Delhi, pp 404. 
Dhingani JC, Solanki KU, Kansara SS. 2013 - Management of root rot disease [Macrophomina phaseolina (Tassi.) Goid] of chickpea through botanicals and oil cakes. The Bioscan 8(3), 73974.

Fazio AT, Papinutti L, Gómez BA, Parera SD, Romero RA, Siracusano G, Maier MS. 2010 - Fungal deterioration of a Jesuit South American polychrome wood sculpture. International Journal of Biodeterioration and Biodegradation 64, 694- 701.

Gajjar DU, Pal AK, Parmar TJ, Arora AI, Ganatra DA, Kayastha FB, Ghadadra BK, Vasavada AR. 2011 Fungal scleral keratitis caused by Phomopsis phoenicicola. Journal of Clinical Microbiology 49, 2365-2368.

Gujarat Ecological Commission 1996 - Biological diversity of Gujarat: Current knowledge. A report compiled and published by Gujarat Ecological Commission, GERI Campus, Race Course Road, Vadodara.

Gujarat State Biotechnology Mission 2013 - Barcoding Fungal Biodiversity of Gujarat, India. (http://btm.gujarat.gov.in/btm/biogene-init.htm).

Katara RS, Patel ND, Sinha M. 2013 - A Clinical Microbiological Study of Corneal Ulcer Patients at Western Gujarat, India. Acta Medica Iranica 51(6), 399-403.

Khan SR, Nirmal Kumar JI, Kumar RN, Patel JG. 2013 - Physicochemical properties, heavy metal content and fungal characterization of an old gasoline contaminated soil site in Anand, Gujarat, India. Environmental and Experimental Biology 11, 137-143.

Khokhar N, Mulla S, Shah L, Vaghela L. 2013 - Characterization of clinical isolates like bacteria and fungi from ocular infection. Journal of Infectious Diseases Letters 2, 12-15.

Korat C, Chopada G, John P. 2013 - Studies on biodiversity of fleshy fungi in Navsari (South Gujarat), India. International Journal of Biodiversity and Conservation 5(8), 508-514.

Koyani, RD, Rajput KS. 2014 - Light microscopic analysis of Tectona grandis L.f. wood inoculated with Irpex lacteus and Phanerochaete chrysosporium. European Journal of Wood and Wood Products 72, 157e164.

Koyani RD, Sanghvi GV, Sharma RK, Rajput KS. 2013 - Contribution of lignin degrading enzymes in decolourisation and degradation of reactive textile dyes. International Biodeterioration and Biodegradation 77, 1-9.

Koyani RD, Sharma RK, Rajput KS. 2014 - Biodegradation of synthetic textile dyes by Mn dependent peroxidase produced by Phanerochaete chrysosporium. International Journal of Environmental Sciences 5, 652-663.

Kumar A, Pandya S, Kavathia G, Antala S, Madan M, Javdeker T. 2011 - Microbial keratitis in Gujarat, Western India: findings from 200 cases. Pan African Medical Journal 10(1), 48-56.

Lee H, Yun SY, Jang S, Kim GH, Kim JJ. 2015 - Bioremediation of polycyclic aromatic hydrocarbons in creosote-contaminated soil by Peniophora incarnata KUC8836. Bioremediation Journal DOI: 10.1080/10889868.2014.939136

Mueller GM, Bills GF, Foster MS. 2004 - Biodiversity of fungi: inventory and monitoring methods. Elsevier Academic Press, San Diego.

Nagadesi PK, Arya A. 2012 - Lignocellulolytic activity of wood inhabiting fungi from Ratanmahal Wildlife Sanctuary Gujarat, India. Advanced Biotech 12(5), 3036.

Nagadesi P. K. and Arya A. 2013 - Rotting of Peltophorum ferrugineum (Decne.) Benth. by pathogenic lignicolous fungi in Rajpipla, Gujarat, India. Journal on New Biological Reports 2(1), 17-27.

Nasit J, Sojitra N, Bhalra R, Gauravi D. 2013 - Aspergillosis of bilateral breast and chest wall in an immune-competent male masquerading as breast cancer. International Journal of Health \& Allied Sciences 2, 212-215.

Nawal P, Patel S, Patel M, Soni S, Khandelwal N. 2012 - A study of superficial mycoses in Tertiary Care Hospital. National Journal of Integrated Research in Medicine 3(1), 90-93.

Panchal P, Pethani J, Patel D, Rathod S, Shah P. 2013 - Analysis of various fungal agents in clinically suspected cases of otomycosis. Indian Journal of Basic \& Applied Medical Research 8, 865869. 
Płaza G, Upchurch R, Brigmon R, Whitman W, Ulfig K. 2004 - Rapid DNA extraction for screening soil filamentous fungi using PCR amplification. Polish Journal of Environmental Studies 13, 315-318.

Ranade VD, Korade ST, Jagtap AV, Ranadive KR. 2012 - Checklist of Myxomycetes from India. Mycosphere DOI: 10.5943/mycosphere/3/3/9

Sanghvi GV, Koyani RD, Rajput KS. 2013 - Anatomical characterisation of teak (Tectona grandis L.f.) wood decayed by fungus Chrysosporium asperatum. Journal of Tropical Forest 25, 547-553

Salvachúa D, Prieto A, López-Abelairas M, Lu-ChauT, Martínez AT, Martínez MJ. 2011 - Fungal pretreatment: an alternative in second-generation ethanol from wheat straw. Bioresource Technology 102, 7500-7506.

Saxena RK, Ranhotra PS. 2009 - Palynofloral study of the intertrappean bed exposed at a new locality in Kutch District, Gujarat and its implications on palaeo-environment and age. Journal of Geological Society of India 74, 690-696.

Shah BP, Chauhan D, Shah DR, Chauhan P, Shah RR. 2013 - Seasonal variation of airborne microflora in dairy processing plant. Species 2(6), 18-22.

Singh S, Beena PM. 2003 - Profile of dermatophyte infections in Baroda. Indian Journal of Dermatology Venereology Leprology 69, 281-283.

Tadvi DS. 2013 - Floristic diversity of Dang, Gujarat. Ph.D. Thesis, The M. S. University of Baroda, Vadodara.

Thaker S, Maharsh R. 2012 - Growth and development of plant pathogenic fungi in define media. European Journal of Experimental Biology 2(1), 44-54.

Webster J, Weber RWS. 2007 - Introduction to fungi (3rd edn). Cambridge University Press, Cambridge.

White T, Bruns T, Lee S, Taylor J. 1990 - Amplification and direct sequencing of fungal ribosomal RNA genes for phylogenetics. In: Innis MA, Gelfand DH, Sninsky JJ, White TJ, (Eds) PCR Protocols: a guide to methods and applications. Academic Press, New York, USA, 315-322.

Yadav SM, Patil RK, Rai AK, Balai LP, Singh S, Niwas R. 2013 - A survey: Occurrence of postharvest rot of aonla and new reported pathogen (Penicillium funiculosum Thom.). Plant Pathology Journal 12(2), 124-126. 